\section{II}

Center for Translational Behavorial Science, 2010 Levy Ave Building B, Suite B0266, Tallahassee, FL 32310

Received 16 February, 2021 Accepted 17 February, 2021 Published 3 March, 2022 Published 3 March, 2022
Issued 3 March, 2022

\section{Correspondence} daniel.dunleavy@med.fsu.edu

Grant Application to: Doris Duke Fellowships for the Promotion of Child Well-Being 2017

\section{License (9) (i)}

\section{This article is licensed under the} Creative Commons Attirbution 4.0 (CC-BY 4.0) license, which allows you to copy, redistribute, transform and build upon the article and all its contents in any medium or format for any purpose, provided that appropriate credit is given.

(C) Dunleavy 2021

\title{
Are We Meeting Best Practice Standards?: A Longitudinal Analysis of Mental Health Practices Within the Florida Child Welfare System with Implications for Child Well-being
}

\author{
Daniel Dunleavy ${ }^{1}$
}

Best practice standards are one method by which medical providers ensure effective care, thus promoting well-being. Though formal guidelines have been recently implemented to direct and standardize children's mental healthcare in Florida, little research has evaluated the extent to which they are executed in practice. This study aims to fill this gap by analyzing Florida Medicaid data. Individual-level data will be collected from a 12-month period from a random sample of children, on Medicaid, with a mental health diagnosis; to: 1) Describe the type and frequency of mental health services provided to this sample, including to those in the child welfare system; 2) Evaluate the extent to which Florida's Psychotherapeutic Medication Treatment Guidelines are adhered to; and 3) Analyze sociodemographic characteristics, to determine if there are predictive factors which account for undertreatment/overtreatment. Data will be coded for congruence with these standards and analyzed using multinomial logistic regression.

Keywords health, best practice guidelines, social work

\section{Research proposal}

General information

Institution of employment at time of application

Florida State University

Prospective host institution

Florida State University

Chapin Hall, University of Chicago

Main field

Social Work

Other fields

Child Welfare

Required length

8/7 pages

Description of the proposed research

Primary research questions

Question \#1 What are the sociodemographic characteristics of children on Medicaid, diagnosed with a mental health condition? Sociodemographic characteristics will further our understanding of how frequently different groups of children are diagnosed with a mental health condition. Diagnoses will be cross-tabulated with age-group, gender, race, place- ment setting, etc. to answer related secondary questions regarding diagnostic prevalence by group.

Question \#2 What types of treatments are being provided to children diagnosed with a mental health condition? Descriptive statistics about type of mental health treatment (i.e. drug and/or psychosocial interventions) will further our understanding about how frequently each type of treatment is provided and how often specific interventions (e.g. cognitive behavioral therapy [CBT], fluoxetine [Prozac]) are utilized. This includes identifying trends in concerning pharmacological practices (e.g. polypharmacy, use of multiple antipsychotics, off-label antipsychotic use; as outlined in Government Accountability Office, 2012, p. 11). This information can be mapped across sociodemographic variables to describe what treatments each subgroup of children (e.g. Medicaid-only vs. child welfare involved children) is receiving. Knowledge gained from this research question can identify if particular groups of children are being differentially treated with respect to their peers in the population; and to determine how these rates compare with national prescription trends (Olfson, Marcus, Weissman, \& Jensen, 2002) and those within the wider child welfare system (Raghaven et al., 2005).

Question \#3 To what extent are the Florida Psychotherapeutic Medication Treatment Guidelines be- 
ing met? The "Florida Guidelines" (Florida Medicaid Drug Therapy Management Program for Behavioral Health, 2017) represent best practice standards. The guidelines are congruent with the most recent research (American Academy of Child and Adolescent Psychiatry, 2015, p, 29; The TADS Team, 2004), which specifies that all children with complex mental health needs should be provided psychosocial therapy concurrently with medication, where possible. Understanding the frequency of guideline adherence will elucidate how often quality, evidencebased mental health treatments are provided. While deviation from guidelines may be occasionally justified (Colbrook, 2005), their consistent implementation is essential to ensure that effective treatments are provided, which help protect and promote child well-being.

Question \#4 What sociodemographic factors are predictive of treatment discrepancies? A multinomial logistic regression will be conducted to determine if particular sociodemographic characteristics are predictive of treatment quality. This analysis will determine whether a child's age-group, gender, race, placement setting, abuse history, etc. increases the odds that they will receive: 1) Recommended care (Guideline adherence); 2) Undertreatment (i.e. no treatment, or treatment lacking medication/psychosocial treatment); or 3) Overtreatment (i.e. polypharmacy, atypical/contraindicated drug use). This information will allow for greater scrutiny within the field and ensure that particular groups of children aren't harmed by extreme deviations in care.

\section{Research approach}

Data Source This dissertation will utilize Florida Medicaid data, which contains records of all children enrolled in Florida's Medicaid program. This dissertation will also utilize a statewide administrative database from the Florida Department of Children and Families (DCF). The Florida Safe Families Network [FSFN] database contains records of each individual child in Florida's child welfare system; and will be used to identify a subgroup of children on Medicaid, in child welfare placement settings, for comparison.

Population My population of interest is children, on Medicaid, in Florida, with a mental health diagnosis. A random sample will be taken from the Florida Medicaid database, from a 12-month period. The sample drawn will be random, in order to facilitate sound statistical inferences to the larger population of children (see Berk, 2004, pp. 39-52). A subgroup of this population (i.e. children in the child welfare system) will be identified within the sample, using their unique Medicaid ID numbers. Merging the information from these two datasets will provide a novel data source, thereby increasing the depth of analyses and the importance of the study's findings

Data access Access to the Medicaid and FSFN databases will be requested in the Spring of 2018, with estimated approval by August of 2018. Permission to use the FSFN database is not an obstacle, as Florida State University's Institute of Child Welfare $(\mathrm{FICW})$ is housed within the College of Social Work. FICW is a key partner with the Florida Department of Children and Families. I've spoken with Dr. Jessica Pryce, director of FICW and a data analyst at the Florida DCF. Both view access to FSFN as feasible and straightforward process. In an effort to investigate the feasibility of using Florida Medicaid data, I am currently working with an AHCA, FloridaMedicaid data analyst to coordinate the data request process. Data received from Medicaid and FSFN will be anonymized, individual-level data. It will be coded into an SPSS dataset and include, among other variables, information about age-group, race, gender, placement setting, and treatment types. Other variables may be collected, pending review of data.

Study design This Iongitudinal study aims to assess the extent to which the Florida Guidelines are adhered to in practice. Data will be collected from a 12-month time period. All cases meeting inclusion/exclusion criteria will be assigned a unique ID number. The sample will be drawn, at random, from this group. Data will be entered into SPSS. Sociodemographic variables (independent variables) will be collected and analyzed for each case. Multinomial logistic regression analyses will be conducted at the end of data collection, to determine what characteristics are predictive of treatment variables/guideline adherence (dependent variables).

Limitations Given the size of Florida Medicaid enrollment, sample size is not perceived as a limitation. Missing data will be analyzed, in order to determine if it is Missing Completely at Random (MCAR). Missing data will be replaced using Multiple Imputation (MI) if methodologically appropriate. A second, more philosophical limitation regards psychiatric diagnosis. Given the current state of psychiatric knowledge, the act of making a diagnosis is a fallible process, relying on descriptive-level, behavioral criteria (Regier et al., 2013). Consequently, some children may be incorrectly diagnosed (false positive diagnosis), while others not in the population under study are incorrectly left undiagnosed (false negative diagnosis). As in all studies of this type, diagnoses are presumed to be correct.

\section{Analytic methods}

Descriptive statistics Descriptive statistics (e.g. frequencies, measures of central tendency, and dispersion) will be reported for all variables in order 
to describe the characteristics of the sample. A cross-tabulation will be conducted to examine the frequency of different types of treatment services and adherence across key sociodemographic variables.

Inferential statistics A multinomial logistic regression was chosen as the method for calculating the odds that a child will receive treatment that adheres to the guidelines, or that can be considered a case of overtreatment or undertreatment. While differences can be noted at the descriptive level, this analysis will help uncover which groups are at greatest risk for deviations in care, by use of frequentist inference methods. The reported odds ratio (OR) serves as the effect size (Tabachnick \& Fidell, 2012, pp. 464-465) of the relationship between the predictor (i.e. IVs) and outcome variables (i.e. DVs); and is reported with the associated confidence in terval (Cl, 95\%; Cumming \& Finch, 2005). Confidence intervals provide an estimation of the precision of the OR (Szumilas, 2010, p. 227). P-values will be reported, as a tool for controlling error rates (i.e. the false positive discovery rate) and will be judged, at a minimum, according to the standard .05 threshold; though recent debates (Benjamin et al., 2018; Colquhoun, 2014; Lakens, 2017) call for a more nuanced approach. Bayesian methods, which include the use of credible intervals (Hoekstra, Morey, Rouder, \& Wagenmakers, 2014), will be considered given the nature of the dataset (see generally Berk, Western, \& Wiess, 1995).

\section{Work plan}

Timeline I have completed all coursework required for my degree and have successfully passed my preliminary examinations. I will begin my prospectus writing in the beginning of January 2018. I plan on defending my prospectus in April of 2018 (04/18) Upon completion I can begin formally securing the data needed for my dissertation. I expect to have approval and access to the Florida Medicaid database by August of 2018 (08/18). I expect to have approval and access to the Florida Department of Children and Families' (DCF) Florida Safe Families Network (FSFN) database by August of 2018. Access to the FSFN database is not viewed as an obstacle. FSU is home to the Florida Institute for Child Welfare (FICW), a key partner to Florida's DCF. Data from across a 12-month period, from these two databases, will be synthesized by September of 2019 (10/19). I expect to have analyzed the data and written my full dissertation by March of 2020 and defend my dissertation by the end of April (04/20). I plan on graduating at the end of the Spring semester of 2020 (05/20).

Relationship with your policy practice mentors My policy mentor is Mr. Robert "Bob" Whitaker. I chose Bob as my policy mentor because he has strongly influenced my professional career. My desire to get my PhD and subsequent research has been greatly informed by his published work and advocacy through the Mad in America Foundation. I value his depth and breadth of knowledge on psychiatric medications, his enthusiasm for the issues surrounding mental healthcare (i.e. diagnosis/etiology, treatment efficacy, long-term treatment outcomes), and passionate efforts to reform the systems of care.

The deepest areas of my knowledge of mental healthcare are related to the issues of diagnostic accuracy, treatment effects, and practice ethics. Bob's work and knowledge complements my own knowledge and work, in that he has extensively covered issues surrounding long-term treatment outcomes and effects on well-being, as well as issues surrounding polypharmacy, off-label prescribing, and bestpractice standards. These latter areas of focus will greatly inform my dissertation work. Bob's ability to interpret discrepancies in treatment delivery, will help me to identify and operationalize instances of undertreatment and overtreatment. Similarly, Bob's knowledge of best practice standards will help me advocate for practice- and legislative-level changes in children's mental healthcare.

During the fellowship, I will be regularly in touch with Bob via phone, video chat, and email. It is also likely that we will meet during the fellowship timeframe at academic conferences to discuss issues in the field and progress of my research. I hope to utilize the mentor relationship to help disseminate my research findings, to reach a diverse array of mental health stakeholders (e.g. researchers, clinicians, advocates/policy-makers, consumers/families), and to become better versed in the nuances of policychange and policy-advocacy. I am ecstatic to have the opportunity to learn and grow as a professional and scholar from Bob.

\section{Knowledge utilisation}

Policy practice implications

Whatever their inherent limitations, when properly implemented, practice guidelines help curb extreme deviations in care (i.e. undertreatment, overtreatment). The implications of this study are twofold. It will: 1) Improve social and emotional well-being by ensuring that evidence-based treatments are provided; and to 2) Identify and reduce the harm caused to children by extreme deviation in care. Identification of groups that might be at higher risk of receiving undertreatment or overtreatment will lead to greater institutional oversight and attention by staff in practice settings. These goals are congruent with the national efforts to standardize healthcare practice (Institute of Medicine, 1990; 2011), with federal and institutional calls for greater oversight over childhood medication prescription (Government Accountability Office, 2011, 2012, 2017; Leslie, 2010), 
and with the concerns of child welfare researchers (Mackie et al., 2016) and legal scholars (Strawbridge, 2011).

Ensuring the provision of evidence-based treatment Childhood physical and sexual abuse and neglect are strongly associated with the development of childhood mental health problems (Administration for Children \& Families, 2012) and the development of later adult psychopathology (Guadiano \& Zimmerman, 2010; Matheson, 2013; Read \& Bentall, 2012; Read, van Os, Morrison, \& Pam, 2005). Therefore, addressing mental health problems of children on Medicaid and in the child welfare system is essential for promoting current and future well-being. An analysis of Florida Guideline implementation, will ensure that children diagnosed with mental health conditions are and will receive appropriate care.

Preventing the neglect and abuse of children's mental healthcare. In Florida, failure to provide proper mental healthcare can legally be considered a form of child neglect (Child Welfare Information Gateway, 2015). As the Florida Guidelines represent best practice standards, failure to consistently implement these guidelines in child welfare systems can be regarded as a form of institutional child neglect. The consequences of neglecting mental health problems are severe. Untreated depression can lead to a worsening of symptoms, resulting in suicide, selfharm, decreased academic performance (Kovacs \& Goldston, 1991), and social deficits ( Geller, Zimerman, Williams, Bolhofner, \& Craney, 2001). In other words, untreated mental health problems can be detrimental, if not seriously harmful, to a child's well-being. Likewise, overtreatment (overmedication, polypharmacy, and off-label prescription) can lead to serious physical and mental health problems; a trend some call "pharmacological abuse" (Healy, 2009, pp. 272-273). Overtreatment is not uncommon in child welfare systems, where children are 2-3 times more likely to be medicated than their peers in the community (Crimson \& Argo, 2009; Raghavan, 2005). Foster care children are estimated to be medicated at a rate 3-13 times that of their peers (Leslie et al., 2010). Children on Medicaid are prescribed antipsychotics at twice the rate of those privately insured (Government Accountability Office, 2012). This is concerning since overtreatment can increase the rate of adverse effects (Whitaker, 2010), which include: akathisia (Loonen \& Stahl, 2011), suicidality (Bielefeldt, Danborg, \& Gøtzsche, 2016; Healy, 2005), and physical dependence syndromes (Fava et al., 2015). Long-term antipsychotic use, is associated with progressive reduction in brain volume (Fusar-Poli et al., 2013) and Parkinson's-like movement disorders (American Psychiatric Association, 1992). Thus, identifying cases of overtreatment (and undertreatment) will promote children's physical and mental well-being, prevent harmful trends in treatment practice, and lead to policy change.

\section{Cost estimates}

Total budget requested

30.000 \$ US

Intended starting date

August 2018

Application for additional grants

None

Data management plan

N.A.

Ethics

N.A.

Society

Public summary

N.A.

\section{Reviews}

N.A.

\section{Rebuttal}

N.A.

\section{Decision}

\section{Doris duke fellowships application}

Doris Duke Fellowships<DDFellowships@chapinhall.org>

Tue 3/13/2018 9:18 PM

To: Daniel Dunleavy <djd09e@fsu.edu>

Dear Dan,

Thank you for applying to the Doris Duke Fellowships for the Promotion of Child Well-Being and participating in atelephone interview for finalists. Unfortunately, after careful consideration, the selection committee did not selectyour application for the fellowship. It was a very difficult decision that does not necessarily reflect on the quality orrelevance of your proposed research. In selecting the cohort, every attempt is made to achieve a group of scholarsthat will complement each other's skills and represent a diversity of disciplinary perspectives, research interests, and professional experiences. Our final selection is difficult, particularly when the finalists are as highly qualifiedas they were this year.

We greatly appreciate your interest in the fellowship and regret that we are not able to offer you an 
award. We wishyou the best of luck in completing your dissertation research and in your future endeavors, and hope that you willcontinue to focus on the prevention of child abuse and neglect.

Sincerely,

Deborah Daro, PhD.

Chair of the Selection Committee

Doris Duke Fellowships for the Promotion of Child Well-Being

Senior Research Fellow

Chapin Hall at the University of Chicago

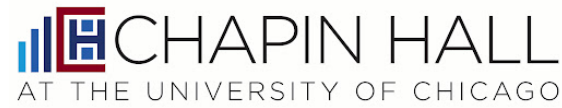

\section{References}

Administration for children and families. (2012). Information memorandum: Promoting social and emotional well-being for children and youth receiving child welfare services. U.S. Department of Health and Human Services. https://www.acf.hhs.gov/sites/default/files/cb/ im1204.pdf

American Academy of Child and Adolescent Psychiatry. (2015). Recommendations about the use of psychotropic medications for children and adolescents in child-serving systems. https : / / www . aacap. org / App Themes/AACAP/docs/clinical_practice center/ systems_of_care/AACAP_Psychotropic_Medication_ Recommendations_2015_FinAL.pdf

American Psychiatric Association. (1992). Tardive dyskinesia: A task force report of the American Psychiatric Association. American Psychiatric Association.

Benjamin, D. J., Berger, J. O., Johannesson, M., Nosek, B. A., Wagenmakers, E.-J., Berk, R., Bollen, K. A., Brembs, B., Brown, L., Camerer, C., Cesarini, D., Chambers, C. D., Clyde, M., Cook, T. D., De Boeck, P., Dienes, Z., Dreber, A., Easwaran, K., Efferson, C., ... Johnson, V. E. (2018). Redefine statistical significance. Nature Human Behaviour, 2(1), 6-10. https://doi.org/10.1038/s41562-017-0189-z

Berk, R. (2004). Regression analysis: A constructive critique. Sage Publications, Inc.

Berk, R. A., Western, B., \& Weiss, R. E. (1995). Statistical Inference for Apparent Populations. Sociological Methodology, 25, 421. https://doi.org/10.2307/271073

Bielefeldt, A. Ø., Danborg, P. B., \& Gøtzsche, P. C. (2016). Precursors to suicidality and violence on antidepressants: Systematic review of trials in adult healthy volunteers. Journal of the Royal Society of Medicine, 109(10), 381-392. https://doi.org/10.1177/0141076816666805

Caroff, S., Miller, D., \& Rosenheck, R. (2010). Extrapyramidal side effects. In T. Stroup \& J. Lieberman (Eds.), Antipsychotic trials in schizophrenia (pp. 156-306). Cambridge University Press.

Child Welfare Information Gateway. (2015). Definitions of child abuse and neglect. U.S. https://www.childwelfare. gov/pubPDFs/define.pdf

Colbrook, P. (2005). Can you ignore guidelines? British Medical Journal Careers, 143-144.
Colquhoun, D. (2014). An investigation of the false discovery rate and the misinterpretation of $p$-values. Royal Society Open Science, 1(3), 140216. https://doi.org/10. 1098/rsos.140216

Crimson, M., \& Argo, T. (2009). The use of psychotropic medication for children in foster care. Child Welfare, $88(1), 71-100$

Cumming, G., \& Finch, S. (2005). Inference by Eye: Confidence Intervals and How to Read Pictures of Data. American Psychologist, 60(2), 170-180. https://doi.org/10. 1037/0003-066x.60.2.170

Fava, G. A., Gatti, A., Belaise, C., Guidi, J., \& Offidani, E. (2015). Withdrawal Symptoms after Selective Serotonin Reuptake Inhibitor Discontinuation: A Systematic Review. Psychotherapy and Psychosomatics, 84(2), 72-81. https:// doi.org/10.1159/000370338

Florida Medicaid Drug Therapy Management Program for Behavioral Health [FMDRMP]. (2017). Florida Psychotherapeutic Medication Guidelines for Children and Adolescents. http : / / www . medicaidmentalhealth org / _assets / file / Guidelines / 2016 \% 20Florida \% 20Best \% 20Practice \% 20Medication \% 20Child \% 20 \%20Adolescent\%20Guidelines.pdf

Fusar-Poli, P., Smieskova, R., Kempton, M., Ho, B., Andreasen, N., \& Borgwardt, S. (2013). Progressive brain changes in schizophrenia related to antipsychotic treatment? A meta-analysis of longitudinal MRI studies. Neuroscience \& Biobehavioral Reviews, 37(8), 1680-1691. https://doi.org/10.1016/j.neubiorev.2013.06.001

Gateway, C. W. I., Health, U., \& Services, H. (2016). Definitions of child abuse and neglect. https : / / www childwelfare.gov/pubPDFs/define.pdf

Gaudiano, B. A., \& Zimmerman, M. (2009). The relationship between childhood trauma history and the psychotic subtype of major depression: Childhood trauma and psychotic depression. Acta Psychiatrica Scandinavica, 121(6), 462-470. https://doi.org/10.1111/j.16000447.2009.01477.x

Geller, B., Zimerman, B., Williams, M., Bolhofner, K., \& Craney, J. L. (2001). Bipolar Disorder at Prospective Follow-Up of Adults Who Had Prepubertal Major Depressive Disorder. American Journal of Psychiatry, 158(1), 125-127. https://doi.org/10.1176/appi.ajp.158.1.125

Government Accountability Office. (2011). HHS Guidance could help sates improve oversight of psychotropic prescriptions. http://www.gao.gov/assets/590/586906.pdf

Government Accountability Office. (2012). Concerns remain about appropriate services for children in Medicaid and foster care. http://www.gao.gov/assets/660/ 650716.pdf

Government Accountability Office. (2017). Foster care HHS has taken steps to support states' oversight of psychotropic medications, bust additional assistance could further collaboration. http://www.gao.gov/assets/690/ 681916.pdf

Guadiano, B., \& Zimmerman, M. (2010). The relationship between childhood trauma history and the psychotic subtype of major depression. Acta psychiatrica Scandinavica, 121(6), 462-470. https://doi.org/10.1111/j.16000447.2009.01477.x

Healy, D. (2009). Psychiatric drugs explained (5th ed.). Churchill Livingston.

Healy, D., \& Aldred, G. (2005). Antidepressant drug use \& the risk of suicide. International Review of Psychiatry, 17(3), 163-172. https : / / doi . org / 10.1080/ 09540260500071624 
Hoekstra, R., Morey, R. D., Rouder, J. N., \& Wagenmakers, E.-J. (2014). Robust misinterpretation of confidence intervals. Psychonomic Bulletin \& Review, 21(5), 1157-1164. https://doi.org/10.3758/s13423-013-0572-3

Institute of Medicine. (1990). Clinical practice guidelines: Directions for a new program. National Academy Press.

Institute of Medicine. (2011). Clinical practice guidelines we can trust. National Academy Press.

Kovacs, M., \& Goldston, D. (1991). Cognitive and Social Cognitive Development of Depressed Children and Adolescents. Journal of the American Academy of Child \& Adolescent Psychiatry, 30(3), 388-392. https://doi.org/10. 1097/00004583-199105000-00006

Lakens, D., Adolfi, F. G., Albers, C. J., Anvari, F., Apps, M. A. J., Argamon, S. E., van Assen, M. A. L. M., Baguley, T., Becker, R. B., Benning, S. D., Bradford, D. E., Buchanan, E. M., Caldwell, A., van Calster, B., Carlsson, R., Chen, S.-C., Chung, B., Colling, L. J., Collins, G., ... Zwaan, R. A. (2017, September 18). Justify Your Alpha (preprint). PsyArXiv. https://doi.org/10.31234/osf.io/9s3y6

Leslie, L., Mackie, T., Dawdon, E., Bellonci, C., Schoonover, D., Rodday, A., \& Hyde, J. (2010). Multi-state study on psychotropic medication oversight in foster care.

Loonen, A. J., \& Stahl, S. M. (2011). The Mechanism of Druginduced Akathisia. CNS Spectrums, 16(1), 7-10. https: //doi.org/10.1017/s1092852912000107

Mackie, T. I., Hyde, J., Palinkas, L. A., Niemi, E., \& Leslie, L. K. (2017). Fostering Psychotropic Medication Oversight for Children in Foster Care: A National Examination of States' Monitoring Mechanisms. Administration and Policy in Mental Health and Mental Health Services Research, 44(2), 243-257. https://doi.org/10.1007/s10488-016-0721-x

Mackie, T., Hyde, J., Palinkas, L., Niemi, E., \& Leslie, L. (2016). Fostering psychotropic medication oversight for children in foster care: A national examination of states' monitoring mechanisms. Administration and Policy in Mental Health and Mental Health Services Research, 44(2), 243-257. https://doi.org/10.1007/s10488-016-0721-x

March, J., Silva, S., Petrycki, S., Curry, J., Wells, K., Fairbank, J., \& Team, T. (2004). Fluoxetine, cognitive-behavioral therapy, and their combination for adolescents with depression: Treatment for Adolescents with Depression Study (TADS) randomized controlled trial. Journal of the American Medical Association, 292(7), 807-820. https: //doi.org/10.1001/jama.292.7.807

Matheson, S. L., Shepherd, A. M., Pinchbeck, R. M., Laurens, K. R., \& Carr, V. J. (2013). Childhood adversity in schizophrenia: A systematic meta-analysis. Psychological Medicine, 43(2), 225-238. https://doi.org/10.1017/ s0033291712000785

Olfson, M., Marcus, S. C., Weissman, M. M., \& Jensen, P. S. (2002). National Trends in the Use of Psychotropic Medications by Children. Journal of the American Academy of Child \& Adolescent Psychiatry, 41(5), 514-521. https: //doi.org/10.1097/00004583-200205000-00008

Pecora, P., Jensen, P., Romanelli, L., Jackson, L., \& Ortiz, A. (2009). Mental health services for children placed in Foster Care: An overview of current challenges. Child Welfare, 88(1), 5-26.

Raghavan, R., Zima, B. T., Andersen, R. M., Leibowitz, A. A., Schuster, M. A., \& Landsverk, J. (2005). Psychotropic Medication Use in a National Probability Sample of Children in the Child Welfare System. Journal of Child and Adolescent Psychopharmacology, 15(1), 97-106. https: //doi.org/10.1089/cap.2005.15.97

Read, J., \& Bentall, R. (2012). Negative childhood experiences and mental health: Theoretical, clinical, and pri- mary prevention implications. The British Journal of Psychiatry, 200, 89-91. https://doi.org/10.1192/bjp.bp.111. 096727

Read, J., Os, J., Morrison, A., \& Ross, C. (2005). Childhood trauma, psychosis and schizophrenia: A literature review with theoretical and clinical implications. Acta psychiatrica Scandinavica, 112, 330-350. https://doi.org/10. 1111/j.1600-0447.2005.00634.x

Regier, D. A., Narrow, W. E., Clarke, D. E., Kraemer, H. C., Kuramoto, S. J., Kuhl, E. A., \& Kupfer, D. J. (2013). DSM5 Field Trials in the United States and Canada, Part II: Test-Retest Reliability of Selected Categorical Diagnoses. American Journal of Psychiatry, 170(1), 59-70. https://doi. org/10.1176/appi.ajp.2012.12070999

Strawbridge, K. (2011). The children are crying: The need for change in Florida management of psychotropic medication to foster children. U.C. Davis Journal of Juvenile Law and Policy, 15(2), 247-257.

Szumilas, M. (2010). Explaining odds ratios. Journal of the Canadian Academy of Child and Adolescent Psychiatry, 19(3), 227-229.

Tabachnick, B., \& Fidell, L. (2012). Using multivariate statistics (6th ed.). Pearson.

Treatment for Adolescents With Depression Study (TADS) Team. (2004). Fluoxetine, Cognitive-Behavioral Therapy, and Their Combination for Adolescents With Depression: Treatment for Adolescents With Depression Study (TADS) Randomized Controlled Trial. JAMA, 292(7), 807. https://doi.org/10.1001/jama.292.7.807

Whitaker, R. (2010). Anatomy of an epidemic: Magic bullets, psychiatric drugs, and the astonishing rise of mental illness in America. Crown. 


\section{Appendix}

\section{Personal statement \\ Your expected benefits from the fellowship}

Interdisciplinary perspective Interdisciplinary work has been an extremely valuable part of my professional and academic development. In my professional experience, I have worked as a social worker among physicians, nurses, psychologists, supportstaff, and other social workers. Each has enriched my experience by offering a unique lens from which to understand my clients and the challenges faced as part of a professional team. At the academic level, my education has been unquestionably enriched by taking courses across fields. It has provided me the opportunity to learn from researchers in the fields of Sociology, Psychology, Philosophy, Medicine, and Public Health, and has taught me how to analyze social problems from a variety of perspectives.

One of the things which I am looking forward to most, as a fellow, is collaborating with and becoming enriched by the Doris Duke Fellowship and its multidisciplinary peer learning network. Undoubtedly, the fellowship's interdisciplinary perspective and emphasis will help shape my approach and research regarding child well-being, as well as the scope of the issues surrounding providing mental healthcare to children, both within and outside the child welfare system. Considering that previous cohorts have been comprised of fellows from the fields of Sociology, Psychology, Education, Public Policy, Criminal Justice, Social Work, and Public Health (among others), I believe that my work and how I understand these social problems, will only become further enriched and refined.

Peer learning network The feedback that I receive most frequently from my academic peers is that I have an insatiable appetite for knowledge. I continuously strive to learn, to understand the world around me, and to solve important social problems. As a classmate and colleague, I am attentive, offer constructive feedback, and engage thoughtfully with new ideas, even where they diverge from my own particular research interests. These are personal strengths which I can contribute to the work of other fellows. While I do not pretend to know everything about every topic, I always try to sincerely and thoughtfully engage with an issue. I try to use my critical thinking skills to help others refine their ideas and to provide constructive feedback. I attribute these assets to my supplementary coursework and interest in philosophy, a field which has helped me to greatly clarify and explicate my own ideas and arguments. As described in the previous section*, one of the things I benefit from most as a social worker and academic is different perspectives. I believe the Peer Learning Network will allow me to engage with fellows from disciplines both similar to and quite different from my own, exposing me to new ideas, perspectives, arguments, and resources. It is clear to me that the peer network has great potential to improve and refine my research and ideas; as well as for me to contribute to the intellectual development and growth of other fellows. This aspect of the fellowship is among the most exciting opportunities available to me in my academic and professional development.

\section{Looking forward}

Immediate plans following graduation

Immediate professional goals My immediate plans following graduation are to secure a tenure-track position in a school of Social Work at a research university in the United States or related policy center. This will be a place where I can continue researching on child welfare, mental health, and help foster "good research practices" both within my profession and within child welfare research. Additionally, I aim to teach classes related to child welfare, psychopathology, and social policy. While research is my primary motivation for coming into academia, this latter role of teacher is no less important to me. I believe that helping develop the next generation of social workers, many of whom will work with children in some respect, is of the utmost importance in ensuring that our policies and practices are successfully implemented.

Immediate research plans I hope to extend my dissertation work, by seeking funding from federal, state, and non-governmental organizations (NGOs). I aim to analyze mental health practice guidelines in child welfare systems across the nation, to analyze how children's mental health services are provided nationally, and to engage with policy reform to improve child well-being and mental functioning This research agenda would allow for the attempted replication of the findings from my dissertation, a hallmark of rigorous scientific research.

Long term career aspirations My long-term aspirations can be divided into three non-exclusive parts. My goals are to: 1) Refine our understanding about mental health treatment effects, particularly with children; to 2) Contribute to the improvement of children's mental health policy and practice locally and nationally; and to 3) Improve the quality of child welfare research.

Goal \#1 My most important long-term goal is to use information gathered about state guidelines (described in Immediate Plans above), along with knowledge of long-term treatment efficacy/safety (see point 2 below), to ensure that the mental health guidelines utilized in each state are truly evidencebased and reflect 'best-practice' standards for children. I plan on using information gathered about 
discrepancies in guideline adherence to ensure that these improved standards are effectively implemented with all vulnerable children, once they are in place.

Goal \#2 Despite enormous research funding, few studies have been undertaken describing the longterm benefits, harms, and efficacy of many mental health treatments frequently used with children. Long-term evaluation will help us to develop more effective policies and practices for vulnerable children with mental health needs. While effective guideline implementation will minimize extreme deviations in care, this goal will evaluate the long-term effects of services.

Goal \#3 "Good research" is founded on rigorous research methodology, sound statistical inferences, attempted replication and transparent/open research practices. This is true of child welfare research and the long-term areas of research outlined above. I aim to advocate for, research, teach, and practice "good research practices", as exemplified by the Center for Open Science, Society for Improving
Psychological Science, and others.

Is there anything else you want to share with the selection committee I am thrilled to have the opportunity to be considered as a Doris Duke Fellow. The Foundation's mission, to develop and disseminate knowledge; and the Fellowship's goal of creating long-lasting improvement in child well-being, strongly coheres with my own research goals and ethos. This is my second time applying for the fellowship. The past year has provided me the opportunity to clarify and refine my research topics and goals. I am reapplying because I strongly value the opportunity to engage with, collaborate, and learn from the Fellowship's members and multidisciplinary peer learning network. It would greatly improve my scholarly work and professional development to be a Fellow. I believe my intellectual drive, critical thinking skills, and strong research background will make me a valued colleague and collaborator within both the Doris Duke Foundation and Fellowship program. Thank you to the Selection Committee for taking the time to consider this application. 